$=5$

$D D E / \varepsilon T / 2,55-1$

G.R.I.P.S COMMISSTON

2628 MENDOCINO AVENUE, SANTA ROSA, CALIFORNIA 95401 (707) 527-2025

\title{
NOTICE ORtY
}

PORTIOUS OF THIS REFORT ARE ILLEEIBLE.

It has been reproduced from the best avallable copy to permit the broadest possible arailablitity.

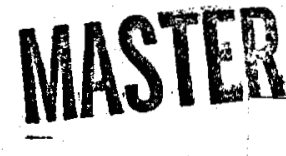

DOE/ET/27155--1

DE82 020977

DESIGN FOR AN INFORMATION-MANAGEMENT SYSTEM
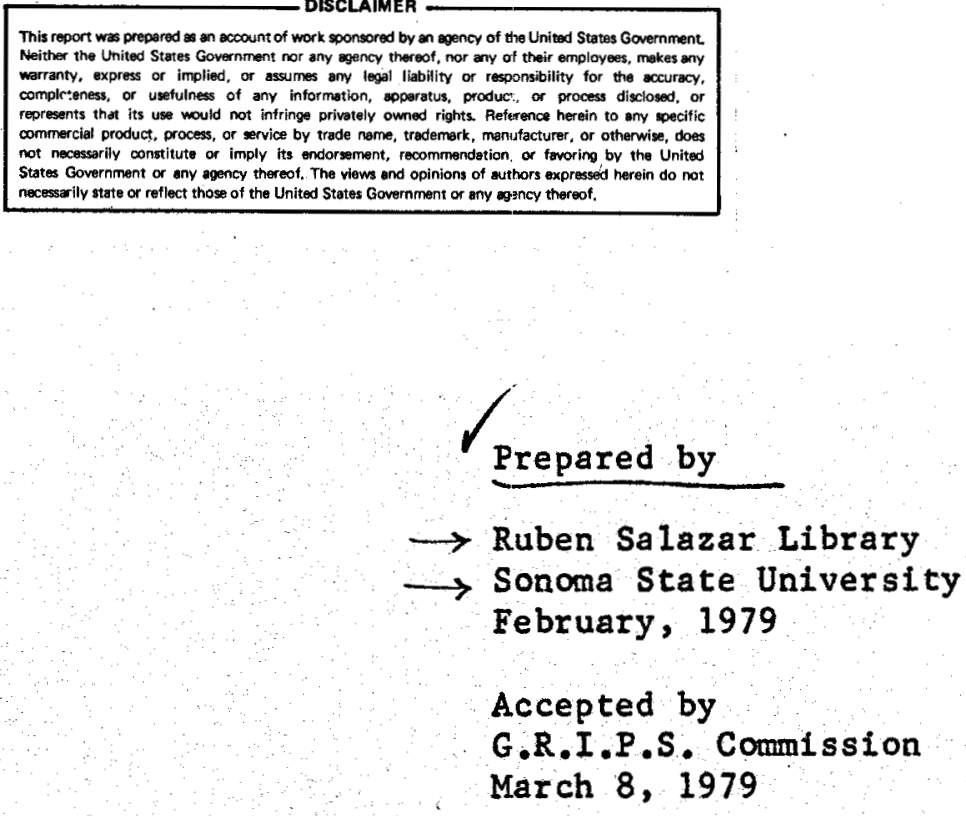

GEOTHERMAL RESEARCH, INFORMATION and PLANNING SERVICES

A California Joint Powers Agency

Lake County

Mendocino County
Napa County

Sonoma County

DISTRIBUTION OF THIS M NIRIMUENT IS UNLIMTTED' 


\section{DISCLAIMER}

This report was prepared as an account of work sponsored by an agency of the United States Government. Neither the United States Government nor any agency Thereof, nor any of their employees, makes any warranty, express or implied, or assumes any legal liability or responsibility for the accuracy, completeness, or usefulness of any information, apparatus, product, or process disclosed, or represents that its use would not infringe privately owned rights. Reference herein to any specific commercial product, process, or service by trade name, trademark, manufacturer, or otherwise does not necessarily constitute or imply its endorsement, recommendation, or favoring by the United States Government or any agency thereof. The views and opinions of authors expressed herein do not necessarily state or reflect those of the United States Government or any agency thereof. 


\section{DISCLAIMER}

Portions of this document may be illegible in electronic image products. Images are produced from the best available original document. 
This Report was prepared with the support of the U. S. Department of Energy, Grant No. ET-78-G-03-2075. However, any opinions, findings, conclusions, or recommendations expressed herein are those of the author and do not necessarily reflect the views of D.O.E. 
Summary

This report provides the design of an information management system to assemble, classify, and catalog existing documentation on the development of the Geysers/Calistoga known Geothermal Resources Area (KGRA). The study, carried out by the Ruben Salazar Library at Sonoma State University, consisted of several components.

1) user need requirements

2) design of the system

3) survey of information management systems

4) systems analysis and cost proposal

User input concerning information requirements and system characteristics were obtained from interviews (personal and telephone) and a questionnaire. The sample user population expressed a need for the identification and access to relevant information concerning local geothermal development. Furthermore, it was a consensus of opinion that the creation of an information center as a depository for relevant documentation would be useful in meeting information needs. Sonoma state University was considered an ideal organization to meet this objective.

The information management system vas designed with several criteria in mind.

1) Low maintenance and ease of updating

2) extensive subject access, including geographical coding

3) widespread dissemination of the result

4) use as a research collection rather than just a collection of documents

Thus, the result would be a system with considerable utility as a resource, yet low in maintenance after project termination. To meet these objectives the production of a book catalog utilizing automatic data processing (ADP) and a data base management system (DBMS) approach is proposed.

A book catalog is recommended since once completed, no maintenance would be required; the product could be disseminated in hard copy and microfiche, and indexing would be extensive enough to meet the needs of a complex and disparate user population. The catalog would also contain full bibliographic descriptions for all records as well as abstracts for highly significant documents. Opdating would be a relatively low effort task. 
Two levels of information management systems support were determined as alternatives for the project. The first level would support the production of the book catalog. The in-house conputing capability at Sonoma state University would sufficiently meet the ADP requirements at this level. The second level would also produce the book catalog but, in addition, would provide an on-line, remotely accessible interactive search capability. The advantages of the second level would be to extend the range of subject (including geographical) access beyond the printed indices. By using Boolean operators concepts rather than words could be used as a searching profile. Thus, specialized bibliographies could be generated tailored to the specific needs of the end user. Access would also be enhanced since the system could be tied into with any remote terminal and an easily obtainable account number. The ideal support system for the second level would be stanford University's SPIRES system.

The cost for the first level system would be $\$ 86,454$. The second level system would be $\$ 106,454$. These would be one year operating costs. The time frame would be approximately six months to produce a catalog containing the retrospective collection. The remaining six months would be for supplements and providing information services such as reference and referral. Alternative systems and estimated costs have been provided in the appendix. 
Introcuction:

In November, 1978, GRIPS' Executive Director, Robert VanHorn negotiated with the Ruben Salazar Iibrary at Sonoma state University to design an information system which would aid in the objective of the GRIPS commission: To develop and use a cooperative environmental data collection and use system including natural, social and economic considerations to facilitate the independent decisions of the four counties of the GRIPS Joint Powers Agreement, and those of state and federal agencies related to the environmental effects of geothermal cevelopment.

Specifically, the system would expedite the transfer of scientific and technical information among the various organizations, private and public, as well as providing information to individuals. The system would allow a free flow of information by providing a centralized entity to identify and bring together documentation on local geothermal development. objective:

Several key elements are required in achieving this

1) Identify comprehensively and exhaustively the information germane to the development of geothermal energy in the Geysers-Calistoga KGRA, including the location of the docurent (see Appendix A).

2) Provide a means of selecting specific records relative to particular needs, i.e., indices: subject, geographic locations, etc.

3) Disseminating the above information to as many concerned organizations and individuals as possible.

4) Development of a centralized library containing as many of the documents as possible.

5) Maintaining an updating program to keep abreast of new information and disseminate this supplemental information.

Items $2+3$, can be met by producing a catalog and indexing system. To meet the criteria of widespread aissemination, the catalog would need to be in book form. Thus, hard or microfiche copies could be distributed to concerned organizations, e.g., local, state and federal government, public libraries and public interest groups.

Processing of the documents, compiling, updating, indexing, etc. are very labor intensive processes due to their repetitive data handiling characteristics. Consequently, utilizing automatic data processing would be extremely advantageous in managing 
the data base to resolve the labor intensive requirement but more importantly it would result in a system with much greater utility by:

1) producing a dynamic rather than static system, with upward conversion capability,

2) providing a significantly greater range of subject access, allowing the indexing language to evolve as the data base evolves,

3) providing a means to update and produce cohesive cumulative indexes,

4) providing an interactive search capability to extend subject access beyond the printed indices,

5) providing remote access to the data base by mounting the system in a nationally accessible network utilizing commonly known software.

It is envisioned that a number of additional services could be made available from the staff that would be required to carry out this program. The information management team would be in an advantageous position to produce a newsletter or information bulletin on current developments in the Geysers-Calistoga KGRA specifically, and on geothermal energy in particular. The newsletter would be specific to local issues and would, of course, augment rather than duplicate the current Geothermal Eotline prepared by California Division of Oil and Gas. Working with the corpus of information concerning the above topics, the group would be in an immediate position to provide information services such as reference, referral, and information retrieval on peripheral subjects related to geothermal development. Indeed, with the insight on issues/topics gained from maintaining the data base and the support of the SSU academic community, the information center would be in an outstanding position to provide an information resource capability, as well as information management to the GRIPS commission and the four counties it serves.

The components of this proposal are in four parts or tasks:

1) assessment of need for such a system

2) design features of the proposed system

3) survey of information management system which might be applied in this project

4) a systems analysis resulting in a cost and time estimation for developing and operating the system 
The methodology and results of these tasks are addressed in the following sections.

Section II:

Task one-Assessment of Need.

Several documents on the development of geothermal energy at the Geysers-Calistoga KGRA and in California were selected and reviewed to obtain background information on issues, research needs, history and the actors involved.

Subsequently, in collaboration with GRIPS' Director Robert Vanfiorn, a sample population was selected for direct interviews; telephone interviews or to receive questionnaires by mail. The sample population selected represented lead and responsible agencies, county officials, industry, consultants, universities and private citizens (see Appendix B).

The questionnaire was provided by Steven Brooks, a senior at the University of California, Santa Cruz, in environmental planning and was based on a similar investigation to design an environmental information clearing house. Mr. Brooks will use the data as part of his senior research project at UC on the role of information dissemination on the development of geothemal energy at the Geysers-Calistoga KGRA.

Input was obtained from approximately 30 individuals and while there was sore difference of opinion as to the sophistication of the information management system, there was a consensus of opinion that a significant need exists to make information readily accessible to all concerned. Furthermore, there was a consensus of opinion for Sonoma state University to meet this objective. A summary of the user survey and a copy of the questionnaire is included in Appendix B.

The interests concerning geothermal development are quite varied. Accordingly, the literature specific to and directly applicable to geothermal development at the Geysers-Calistoga KGRA reflects this variability, consisting of environmental impact reports, impact statements, government documents from a multitude of agencies, industry documentation, legislation, current research, and technical articles published in professional journals. At this time only an estimate of the volume is possible. Eowever, approximately 2000-2500 titles would need to be ldentified and compiled into a catalog to account for the retrospective coverage. Furthermore, there is also a significant increase 
in information currently being generated on geothermal energy. Thus, the growth rate of information will compound the already existing problem of identification and access for the end users (see Appendix A).

A concern for the equity of information access has been expressed by some interviewees. A need to know exactly what research has been performed, where the reports are located, and current research efforts, are areas which should be addressed. Furthermore, organization of the legislation (county, state and federal) so that pertinent regulations could be retrieved by subject would be highly desirable. Indeed, the documentation on Geysers-Calistoga KGRA development are sequestered throughout the Bay Area with no single organization or document providing an adequate inventory or indexing mechanism to this information. The GRIPS bibliography is perhaps the most comprehensive document available. However, the bibliography is not conducive to subject access since there is no index available. Clearly, an updated and more utilitarian tool is warranted.

Section III:

Task two--Design Feature of the System.

The assessment of user need phase identified three major requirements of the system.

1) identification of documents; past, present and updating

2) access

3) information dissemination

Thus, the requirement is for a centralized library to act as an information center for relevant documents and to execute a retrospective retrieval program. The ideal location would be at the Ruben Salazar Library.

The collection should be thoroughly indexed via descriptive cataloging as to permit effective usage by a broad and disparate clientele. It is proposed that key documents, EIR, EIS, reviews, legislation, etc., also be abstracted to facilitate precision in identifying relevant information.

The catalog should be of a format that will be conducive to distribution, since dissenination would be a priority. A book catalog would, of course, be the obvious choice. A number of hard copies as well as microfiche for distribution would significantly increase the collection value as a public resource.

There are a number of thesauri which could be used to index the collection, Department of Energy, Environmental 
Protection Agency, NTIS, Library of Congress, etc., have specific systems which meet specific needs. The collection on Geysers-Calistoga KGRA development will be highly multidisciplinary, whose needs could best be met by taking appropriate descriptors from the above systems as required. However, one system, the IBI GRID Geothermal thesaurus could be designated as the prime source.

The unit record or main entry would be as follows:

Accession number

Author

Title

PO/SO

Source

Location

Descriptors

$\mathrm{Ab}$.

This includes an assigned, sequential accession identifier or number, author, title, performing organization, sponsoring organization, source, location of the document and assigned description from a controlled vocabulary. Abstracts will be included, as noted previously, for highly significant documents.

The catalog will contain the records arranged by accession number. Several indices will be generated, sorting titles and accession numbers by the following fields: autinor, title, performing and sponsoring organization, descriptors ard text terms from a permutation of key words in the title. Since geographical coding will be included in the descriptor field, sorting by these elements will be in the index.

Abstracting and descriptor assignment could be carried out by graduate and senior students from S.S.U. subject specialization would be a prime factor in selecting these personnel. The work would, of course, be reviewed and supervised by an information specialist directing the profect.

Documents will be collected from the various organizatinns which now have them, either as a donated copy or on an interlibrary loan basis for photocopying or abstracting. Other titles will need to be purchased from government and private sources. References will be Identified from computerized literature searches, existing bibliographies, and by treesearching techniques, i.e., checking retrieved documents for significant references.

Assembled documents will be assigned accession numbers and arranged sequentially. Although, this method will not allow a convenient means of shelf browsing, it is an economical and 
efficient means of handling the collection. The documents, however, will be assigned accession numbers by organizational class clusters. For example, government (federal, state and local), private industry and individual authors will be arranged together in the retrospective collection. organizations will be classed and arranged alphabetically as will document titles within a specific organization.

Catalog supplements will also follow the same structural organization. This arrangement should also be adopted within the GRIPS office as a preferred document management system as it would provide a convenient and cost-effective classification plan. Cataloging would not be necessary due to the proposed book catalog.

Section IV:

Task three--Survey of Information Management systems.

A manual execution of this project will require a significant amount of personnel time as the tasks for preparing cards, forms for interlibrary loans, ordering, tracking document status, typing the final copy, etc. are very labor intensive. The number of catalog cards required to provide the same level of access as proposed would be well over 20,000 . This would not include updated material. Furthermore, incorporating supplemental indexing entries into a cumulative index while attempting to disseminate these records would be a difficult and time consuming task. Distribution of the catalog would be severely handicapped since the cards would have to be photocopied. Overall maintenance of the catalog would also be an added, ongoing expense, e.g., filing corrections and entries, repair of cards (see Appendix c).

Advantages of supporting the project by using automatic data processing and a data base management system (DBMS) approach would be to build a system with unlimited growth potential and upward conversion capability. Prime benefits would be ease in updating indices, greater subject access, and wider dissemination of the information in the data base. General information management systems were investigated to support this project: the Sonoma state Computer Center, stanford Center for Information Processing (SCIP), and the LBL Computer center. SSU computing and SCIP are recommended as possible alternatives to support two levels of data base managenent system development for this project. The two levels envisioned are the 1) production of the book catalog per se, and 2) providing an on-line, remotely accessible, interactive search capability.

The ssu Computer Center would be used for the first level and scIp for the second level. Since the first level would not require extensive programing nor large maniframe capability, the SSU. Computer center has been chosen over. IBI ( $\mathrm{cr}$ any other system) due to the proximity of the SSU computer to the base of operations, the Ruben Salazar library. Should the second level be selected, SCIP would be the preferred choice since it provides the SPIRES 
system (Stanford Public Information Retrieval system). Choosing IBI or any othex system for the interactive level would require developing a system that already exists within SPIRES. Furthermore SPIRES is well known in the research and academic community and is highly user oriented.

Figure 1 provides a schematic representation of the work flow. Citations identified would be keyed into a remote terminal and transferred to the campus computer. A relatively simple program would be prepared to receive the data and then print it out on $5 \times 8$ index cards. These cards would be used extensively in processing documents, assigning descriptors, abstracts, etc. When the machine readable file reached a designated level of completeness, e g.. all government and private organization documentation, the first volume of the catalog would be printed with a second program designed for the sorting component.

The second volume of the catalog would contain docunents prepared by individuals from journals, books, miscellaneous material. etc. These two volumes would cover the retrospective information to date, and the third and successive volume would be supplemental. Indices would, of course, be cumulative.

An advantageous aspect of using a DBMS would be that data from other DBMS could be obtained in machine readable form and transferred directly into the GRIPS system. For instance, data from LBI GRID, EPA, etc., would be received in tape format. similarly, data generated from the GRIPS system could be exchanged in tape form to these organizations. Producing microfiche output would be readily possible through computer output ricrofilm (COM) capabilities.

A second level of development would include the functions described above but, furthemore, would include an interactive capability with the DBMS. Such a capability would allow on-demand specialized, precision sorts of the data utilizing Boolean operators (and, or and not). Furthermore, this capability would greatly increase the disseminating capability of the system. Through remote terminals and utilizing national comunication networks, the information in the system would be accessible without limitation to researchers in Sacramento, national institutes, laboratories, colleges and universities, Washington, etc.

The ideal system to provide this capability, as previously mentioned, would be stanford University's SPIRES. SPIRES meets the criteria which would make the data base remotely accessible. It operates on a well known user-oriented programing language, searching charges are relatively inexpensive (approximately $\$ 15$ per search), accounts are easy to obtain, and expert consultation would be available to help with system development. Furthermore, the potential for expansion would be unlimited as well as conversion options. With a significant increase in geothermal development in sight, throughout the Western United states, the GRIPS-sSU geothermal data base wöld be in an ideal position to take the lead as the public information resource on the subject, while the LBI GRID moved into the direction of statistical and numerical data analysis. It should be noted that SPIRES is also publicly accessible through public liorary networks. 
Figure 1

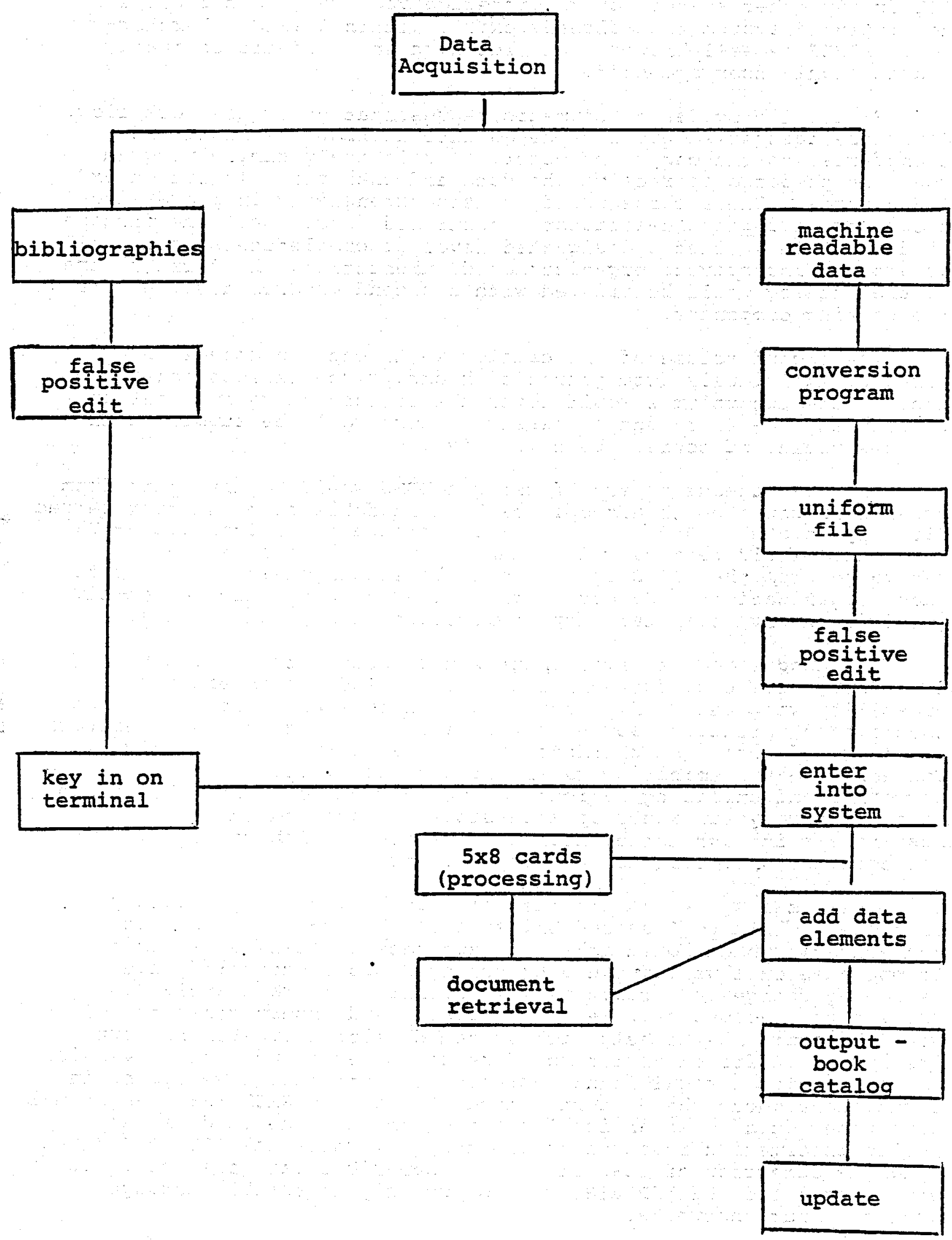


Section V:

Task four--Systems Analysis and cost and Time Estimate.

As mentioned in the preceding section, two levels of program sophistication are proposed:

Plan one, production of a book catalog according to the specification previously described, and

Plan two, in adaition to the elements of plan one, the data base would be mounted on an interactive, remotely accessible system.

The cost breakdown for these plans is itemized on Figure 2 . The total price for plan one is $\$ 86,454$ with $\$ 76,454$ allocated to the Ruben Salazar Iibrary, and $\$ 10,000$ to the sSU Computer Center. Personnel tasks are itemized on Figure 3 .

This estimate is for a one-year operation. The retrospective catalog could be completed within six months after the starting date. It is envisioned that the catalog would be in two volumes. Volume one containing government-related documentation and the second volume containing nongovernmental entries. Volume one could be completed one to two months prior to volume two. The remaining six months would be for supplements and providing information services. Requests for information service would undoubtedly increase dramaticaily once the catalog was disseminated. Operating costs for successive years would depend upon the degree of service required. A minimal budget for effective operations would include maintaining the full-time information specialist and 50 percent reductions for most other items.

The cost for including the plan two element would be an additional $\$ 106,454$. This would include $\$ 5,000$ allocated to the ssu Computer Center, $\$ 20,000$ to Stanford Center for Information Processing (SCIP) (storage, printing, CPU time and a 20 percent overhead), and $\$ 5,000$ for SPIRES programming. The SPIRES programing could be executed in-house at SSU (by the library and the computer center) or by RIIN (Research Iibraries Information Network), a Stanford University affiliate. An advantage to having RIIN program SPIRES would be expediency and no overhead cost. The maximum time estimated by RIIN to complete the system would be three months. These charges are for a one year operation. Subsequent year operations would be approximately 50 percent of the total cost or $\$ 10,000$. It should be noted that a considerable amount of the subsequent year cost is for storage charges. Whereas, considerable reductions in storage charges in the immediate future are expected, the $\$ 10,000$ estimate is probably quite high. 
Figure 2

Proposed Budget

PIAN ONE

Ruben Salazar Library

Information Specialist (1 year)

14,400

Clerical Assistant

fringe benefits e 228

Student Assistants $20-80$ hours \& $\$ 4.00$

fringe benefits e $14 \%$

Total wages, salaries, fringe benefits overhead \& 488

Consultant (Senior Information Specialist)

Supplies and Services

\begin{tabular}{ll}
\hline telephone & 1,000 \\
travel & 1,000 \\
office expense & 1,000 \\
photo copy & 2,500 \\
purchase & 5,000 \\
computer search & 1,000 \\
\hline Ruben Salazar Library &
\end{tabular}

10,200

5,412

8,320

1,164

39,496

18,958

6,500

SSU Computer Center

11,500

76,454

$\frac{10,000}{86,454}$

PLAN TWO

Ruben Salazar Library

SSU Computer Center

SCIP (Stanford University)

SPIRES Programming

76,450

5,000

20,000

5,000

106,454

\section{Computer Charges}

PLAN ONE

SSU Computer Center

initial input

update

sort and print

update sort and print

programing

PLAN TWO

2,500

2,500

2,000

1,000

2,000

SSU Computer Center (remote job entry)

5,000

Stanford Center for Information Processing

file load, print and update 7,500

storage

search

surcharge $16,500 \times 208$

8,000

$\frac{1,000}{16,500}$

SPIRES Programming

$\frac{3,300}{19,800}$

19,800

TOTAL

5,000
29,800 


\section{Figure 3}

Personnel Tasks and Estimated Time

Information Specialist

system design

administration and reference

computer research

screen printouts

locate document

main entry determination

subject headings

abstracting

tree search

update

Clerical Assistant

type and key in data

filing

order

interlibrary loan

request copy

supervise and manage

update

Consultant

system design

review subject

headings and abstracts

locate documents

reference and computer research

Student Assistants assign subject headings abstract documents 
Section VI

Conclusion

The passage of the California Environmental Quality Act of 1970 (CEQA) requires citizen access to environmental information. CEQA requires the lead agencies to collect and make available all information pertinent to the expected consequences of a proposed development. Prior to CEQA, public access to information generated by private consultants and public agencies was difficult to acquire. However, although CEQA mandates access to information, this objective is much less of a reality than it is in theory. The public is significantly handicapped in its efforts to obtain specific information due to the voluminous amount of data compiled, published documentation, legislation, current research, etc. There is no centralized location of this information nor is there an indexing or subject catalog. Although the public undoubtedly lacks information to the greatest degree, they are by no means alone. Public agencies also require greater information access, particularly those agencies involved in the reviewing phase. Clearly, an information center would significantly be beneficial to all concerned.

Dominance of local interests in the environmental and regulatory context of geothermal development is as it should be. Indeed, only if local interest is sufficiently incorporated into the framework for geothermal development can long-range program success and public satisfaction be insured. It is perhaps for this reason that local governments have such regulatory power to veto or modify proposed units or plants.

Thus, public interest significantly affects the permitting process. Since information is the "removal of uncertainty," lack of information will result in a dissenting public for obvious reasons. The result will be to impede putting power on line, the immediate objective of geothermal development.

Therefore, the creation of a geothermal information center, whose only function is to disseminate information objectively, would be to ultimately expedite the development of the GeysersCalistoga RGRA by providing a free flow of information among all the actors involved. 
Appendix A

Search Strategy

The literature relevant to the development of GeysersCalistoga KGRA will be identified in two phases. Phase one will consist of comprehensive, computerized literature searches in major information networks such as Lockheed Retrieval System's DIAIOG, System Development Corporation's ORBIT, and the National Libraries. The Ruben Salazar Library has extensive experience in these systems, which collectively cover the world's published literature from the late 1960's to date. Phase two will consist of reviewing retrieval documents for relevant citations, or tree-searching.

A preliminary investigation was made concerning the volume of data on geothermal development. Approximately 8,000 citations were retrieved from 15 major data bases using the term geothermal as a searching parameter. The data bases and "hits" are as follows :

\section{Data Base}

Geo Archive

Dissertation Abs

Enviroline

APTIC

(Air Pollution Technical

Information Center)

National Agricultural

Iibrary

Engineering Index

Conference Papers

Index

Science citation Index

Science Citation Index

SSIE

U.S. GPO

NTIS

Energyline

Chem Abs

Chem Abs

NIM Toxline
Year

74-

$71-$

66-

$70-$

$70-$

$73-$

$78-$

$74-77$

$75-78$

$76-78$

$64-79$

$71^{-}$

$72-76$

$77-78$

$76-$
43

Volume

1559

41

392

100

969

606

133

444

465

62

1265

869

204

511

61

Total

$\overline{7724}$ 
Appendix A - continued

Approximately 20 percent of the data specifically concerns California and 8 percent concerns the Geysers. These estimates, however, were made by crossing the above sets with the terms California and Geysers. This would not include a significant number of false negatives which were not identified by the terms Geysers or California, but nevertheless would be highly relevant information. Thus, information on geothermal toxicity, engineering, bio-accumulation, raise, etc, athough not specific to the local KGRA would concern this RGRA indirectly.

Estimation of overlaps within the data bases is difficult to make without screening and compiling the citations. There are a number of other data base which would be searched and thus a possible 30 percent duplication might be offset by the added input. There are, however, two facts concerning information on geothermal development, the retrospective literature is voluminous and it is significantly expanding. Almost every data base shows strong increases in volume from 1977-1978 over 1972-1976. The most salient, of which, is a veritable burst in chemical abstracts during this period.

Effective management of the output will be possible by formating the citations by significance and by subject. The wide range of command language available in the data bases will facilitate this procedure. The printouts will then be screened and checked against a master list for new entries to be added to the information management systems collection.

All citations concerning local geothermal development will be included. Information indirectly related as mentioned previously will also be adaed as determined by the project team. The printouts will also be part of the collection and will thus provide comprehensive retrospective coverage on geothermal energy in general. Updating will be managed in a similar fashion with the probability that fewer files will need to be searched as the project team becomes aware of overlap and uniqueness among data bases.

Tree searching will be an ongoing process as every new document retrieved will be screened for relevant citations. Citations deemed relevant will be checked against the master file and unique items will be added.

The tree searching technique will be particularly useful in locating information published prior to computerization of bibliographic data and for information which has never been published but is cited, e.g., consulting firm reports, in-house communications and reports, personnel communications. 
Appendix A - continued

Based on the data above and the number of entries in the GRIPS Bibliography (1785), the proposed data base should include from 2000-2500 citations for the retrospective coverage (prior to 1979). Updating should account for 1000 citations per year. This would account for new material as well as filling in gaps of overlooked information. Thus, the completed data base at the end of a one-year operation would contain 3000-3500 citations. 


\section{APPENDIX B \\ User Survey Summary \\ Sample User Population and Questionnaire with Tabulated Data}

Sample User Population

Tom Cordill, Sonoma county Planning Commission * + Joel Verner, United States Bureau of Land Management * + Charles Wassinger, United States Geological Survey * + John Emig, California Department of Fish and Game * Mike Tolmasoff, North Sonoma County Air Pollution Control * + District

Steve Zaluski, Lake County Air Pollution Control District + Mary Jadiker, Lake County Energy Council +

Donald Johnson, Former Lake County Planning Director/Consultant * + Jerry Heath, Mendocino County Planning Department * + George Frye, Aminoil + Warren Smith, Union oil * Carl Weinberg, Pacific Gas and Electric + Jim Saeidenberger, Republic Geothermal * + Philip Leitner, St. Mary's College * + Jim Roberts, Consultant * Jim Hickey, Napa County Planning Director * Glen Spencer, Consultant + Fred Cunha, North Coast Regional Water Quality Control Board + Marc Druckman, Sonoma State University, Geology * + Terry Wright, Sonoma State University, Geology * + Davia Fredrickson, Sonoma State University, Anthropology + Mark Walters, Gennis and Associates * + Brian Parker, Lake County Planning Department * A. D. Stockton, California Division of Oil and Gas * Robert Freeman, Stanford Research Institute, International + Sidney Philips, National Geothermal Information Resource, IBL + Susan Schwartz, National Geothermal Information Resource, IBL + Rose Towns, North Bay County Iibrary system + Dave Anderson, Geothermal Resources Council +

* = Questionnaire

$+=$ Interview 
Appendix B - continued

\section{User Survey Summary}

An attempt was made to interview each of these individuals to report on the design project and obtain feedback concerning system characteristics. However, not all of these individuals were personally contacted and, consequently, their input was obtained by mail using the attached questionnaire. Everyone on this list provided input to the survey by either interview or questionnaire. In some cases, both modes of communication were used.

The most significant element sought in the survey was whether or not there is a need for the management of information on local geothermal development. With few exceptions the general consensus was that a central depository of documentation would in fact be quite useful. Several individuals felt that critical would be a better term to describe this need. The preferred characteristics of the system by the users parallel the design features in this proposal. These were essentially, subject and geographical access, abstracting and disseminating the final product. The provision of reference service to augment the system was considered very useful. On the question of providing the system on-line, the majority felt such a capability to be useful but were somewhat unsure of the dynamic capability such a system would offer. It is noteworthy that the less enthusiastic concerning on-line capability were nontheless quite interested in how they would access the system, types of terminals required, etc.

The participants interviewed were asked about their opinion concerning Sonoma State University as the location for the information center and its particular role. No argument was presented against Sonoma State University as the location for the information center. The majority volunteered that the University is the obvious site. In fact, several stated the University to be the only location and would rather not have a system if it wasn't going to be at ssu. Several reasons were given for preferring sonoma state: 1) objectivity as an educational, public institution, 2) insured permanence, 3) $10 \mathrm{cal}$ proximity to the area concerned, 4) the lntelligensia of the academic comunity as a resource, 5) in-house expertise.

Several users surveyed noted a strong interest to supply information to the system as well as receive. Thus, the possibility of placing the information center within an interactive network would be advantageous to end users. Several individuals were hoping this would be a feature of the system. In fact, a member of the LBL GRID System envisioned the GRIPS/SSU information center providing a local node to the larger network. 


\section{Appendix C \\ Information Management System Alteinatives}

Proposed in this report was an ideal system to make accessible tine information concerning the development of GeysersCalistoga geothermal region. The main thrust of the plan was widespread dissemination of this information and a high degree of subject access. ADP was proposed to facilitate the program since it would provide greater subject indexing, provide expedient updating, and the output, $i . e .$, annotated records and cumulated indexes, could be readily distributed in the form of a book catalog. The staff carrying out this work would, in adition, provide reference services on demand.

This plan, however, is only one of a number of information systems which could aid in meeting the information needs of the actors involved in local geothermal development. As an alternative, a card catalog could be prepared, the documents assembled in a special collection; and reference services would result in a $\$ 20,000$ price reduction from plan one. This value is derived by eliminating the computer center cost and reducing by 50 percent student assistants and the consultant. Further reductions would of course be possible by eiiminating other components of the system. For instanse, reduce reference services, minimize retrieval of documents, less subject eccess, etc.

A minimal one-year operation will require at least the full-time information specialist, half-time clerical assistant, student assistants, and the supplies and services. This amounts to approximately $\$ 50,000$. For this price, the documentation would be identified, collected, the card catalog prepared and the system maintained over the one-year operation.

The most significant limitation with this plan would be the loss of the concept of information utility that the proposed plan one provides, i.e., having the collection in book catalog format, with abstracts and subject access. In the alternatives, the system becomes merely a depository. At the end of the project, the result will be a static collection with the problen of maintaining the integrity of the catalog. Distribution of the catalog would only be possible by photocopying the cards. 
SACIA SIATE DNTVESSTI TIBRWL

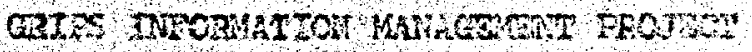

wase

Titro

Orzanatert

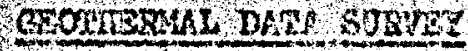

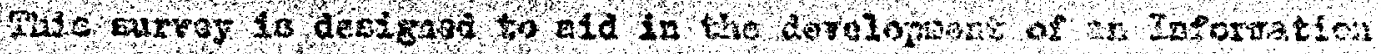

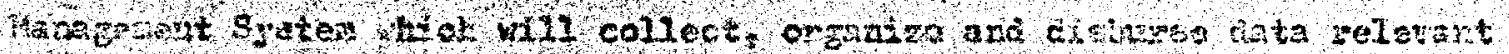

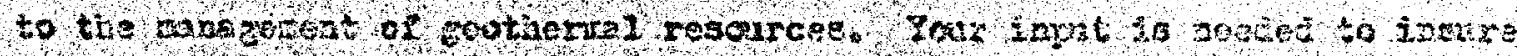

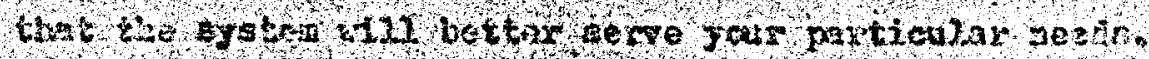

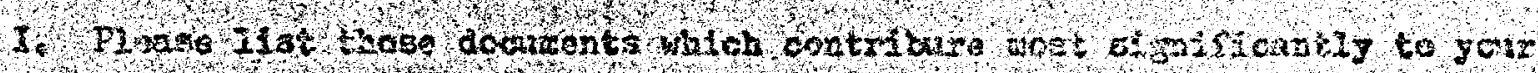

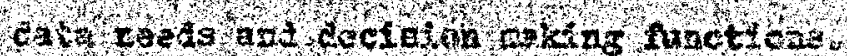

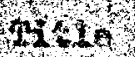

Aloner

Progunarget of vise

Whe rong $1 \mathrm{ng}$ conouts. No notablo pattern.

1.t.

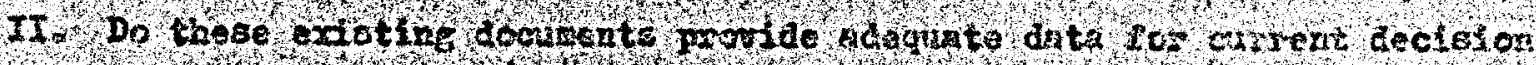

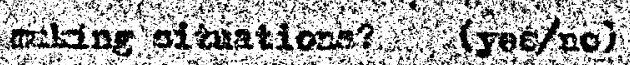

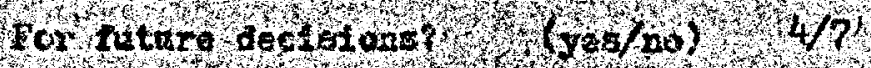

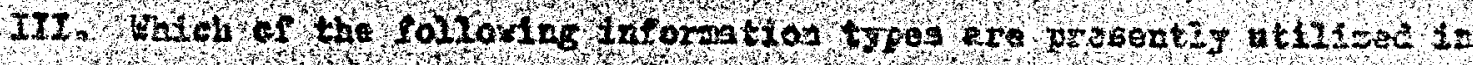

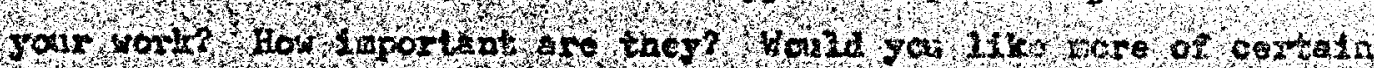
Irropation typer?

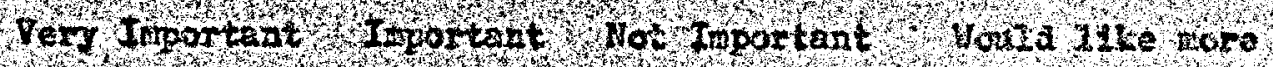

Basic selontelle

revearcho

\section{Applind oclentric} Thasroh

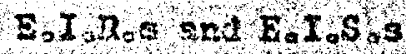

3

\%




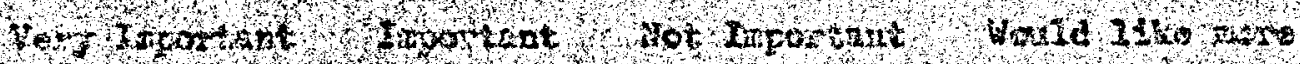

4. Sociogernoti2? studies

- Infordat on on eoragunty

ralues bagarting

Beotheras a dereloptsth

Inforation on 1 ore? politics.

In foreation of otter

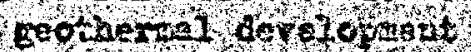
lizalies cat tel te of the toysers calistogerats.

- Inforzat on on buantos end researchers whs $\mathrm{col} 1 \mathrm{C}$ ald yod in rotr bor
3

4

$2+39$

$4+1,124$

4.

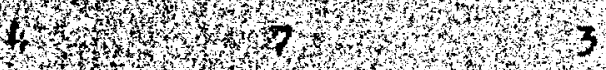

4

4

3

4

4

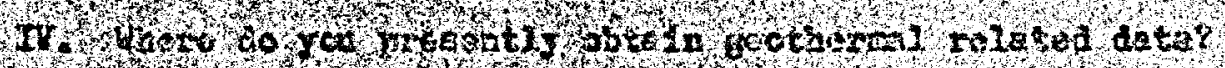

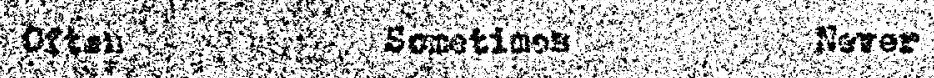

on 8 senor riloa.

4. other otoveter

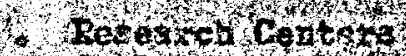

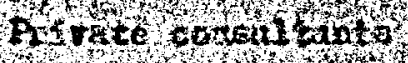

Indostrot stives

43

16

3

6

15.

2

5.

4i.

2

12.

9

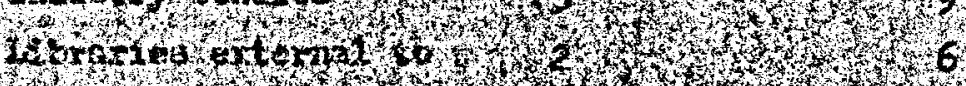

ren ow:

12.

61.6.

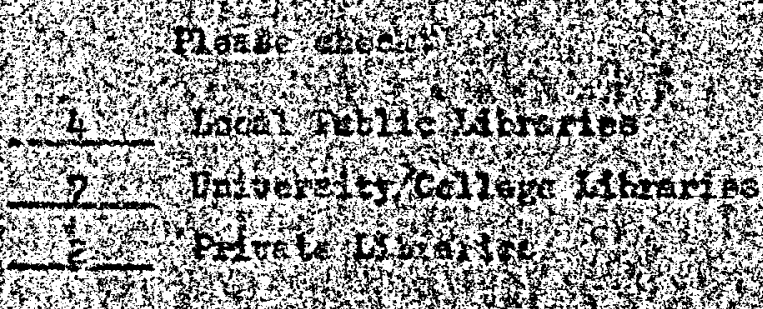

1.7.

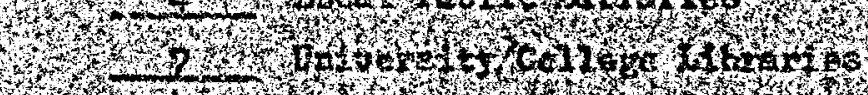

Ty

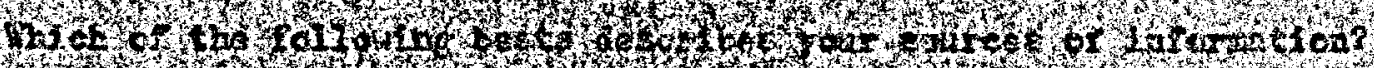

17, H.t.

7.6.7.6.

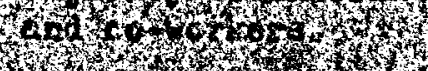

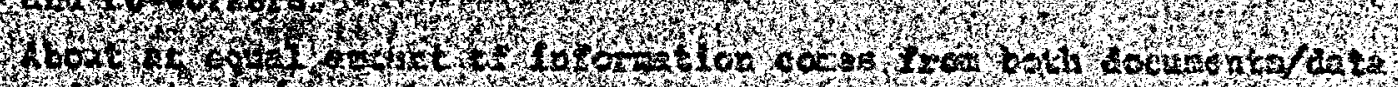

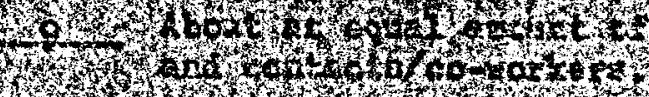

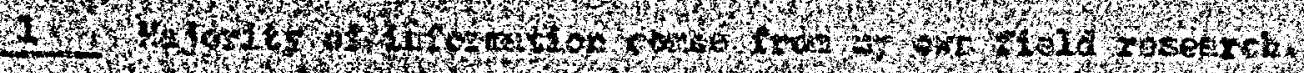

Q.

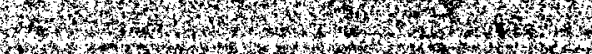

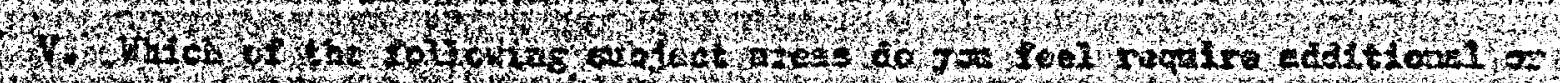

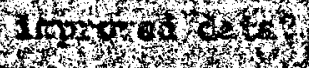

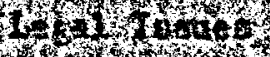

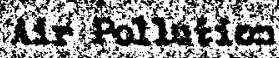

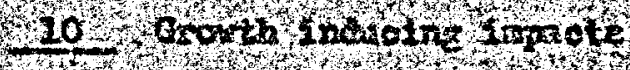

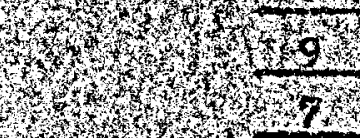

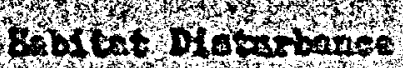
44 sconte Impote

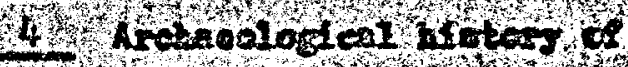 rour area 

A poridas watel a ther for Henros

12

1

ns

Whid roeld 100p net 3 de of now

develepsenth in Eothornal

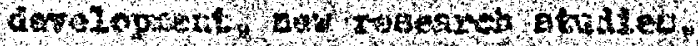

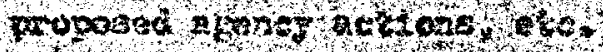

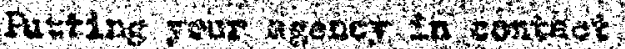

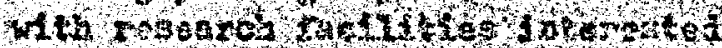

9.

3

3

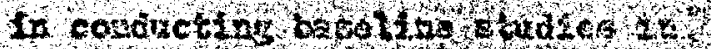

row ares;

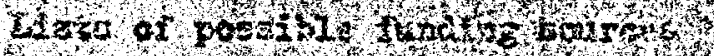

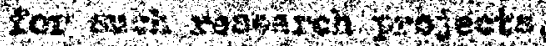

1)

1

?

Intormatiose.680.

W.1.

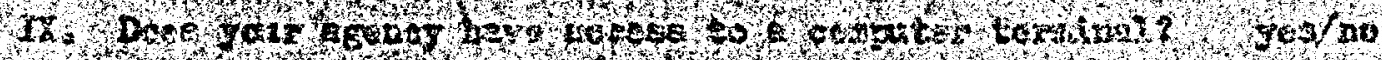
$7 / 9$

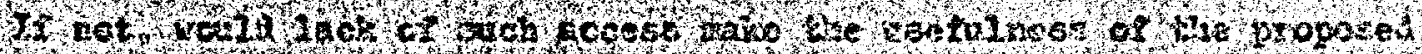

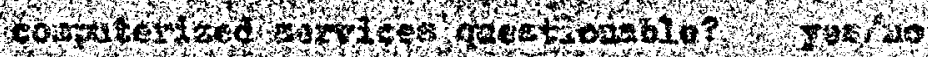

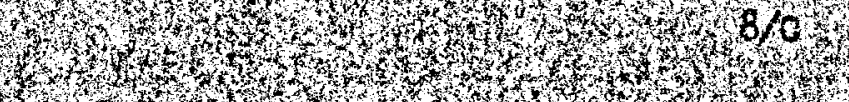

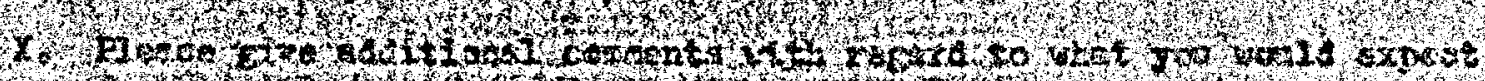

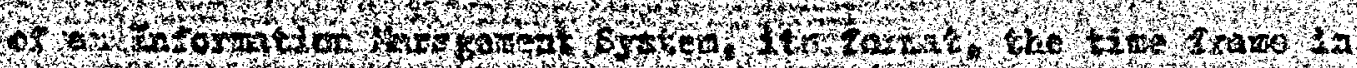

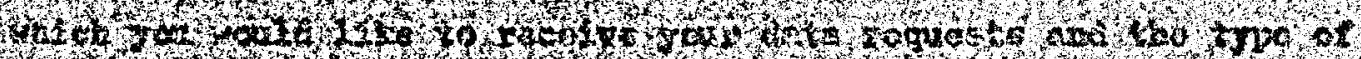

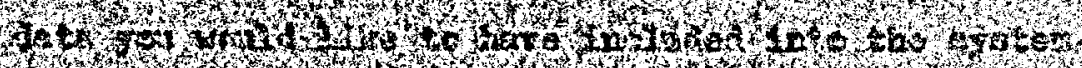

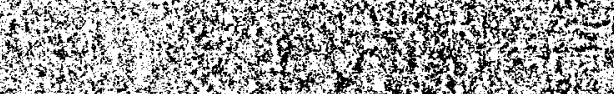

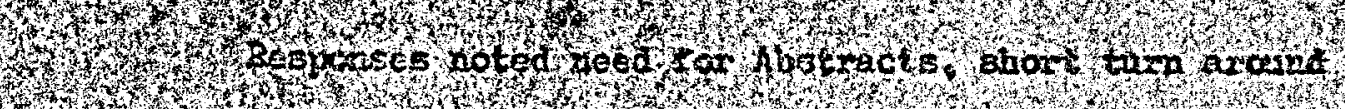

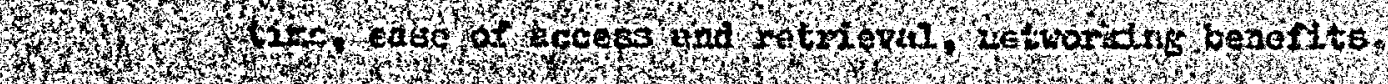

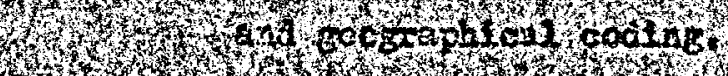

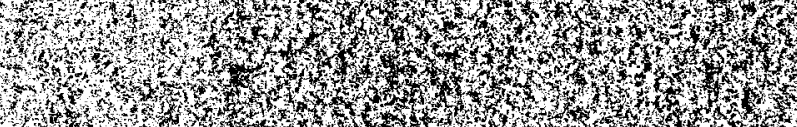

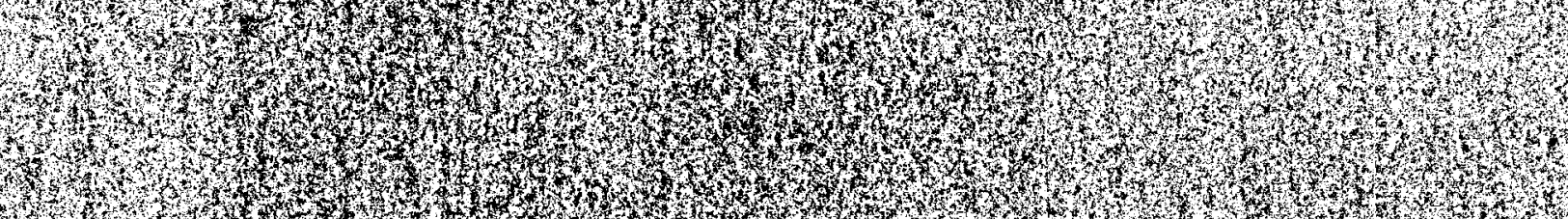

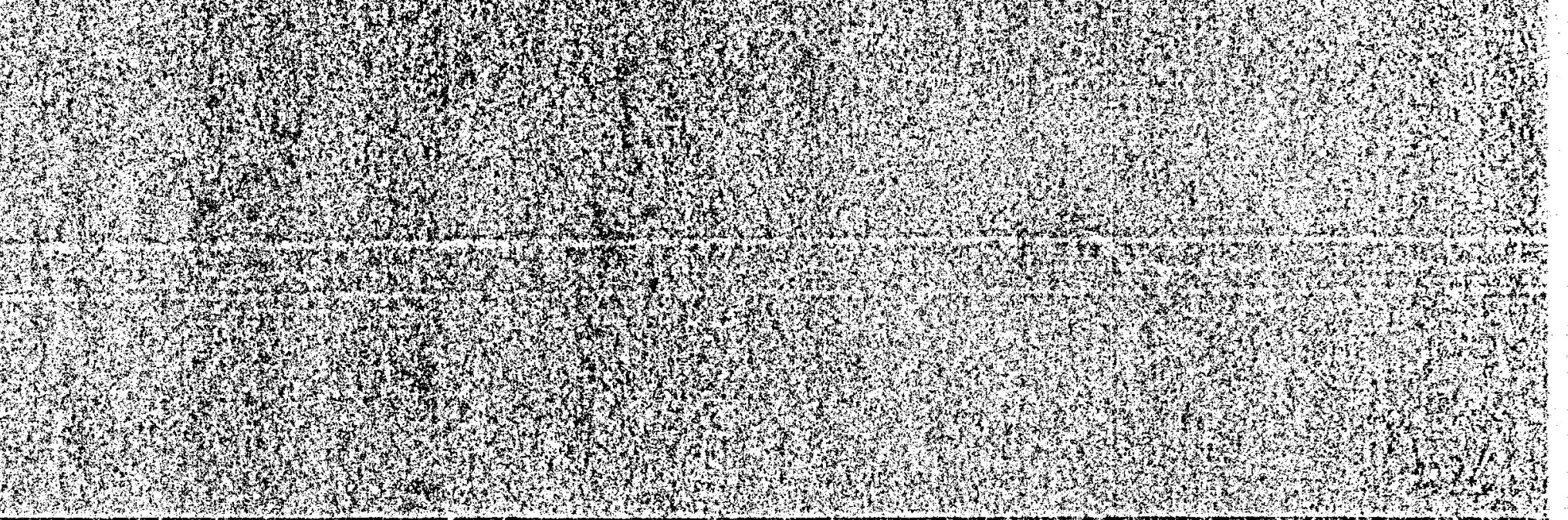

